\title{
Comparison of the Effects of Diclofenac and Acetaminophen Suppositories on Post Hemorrhoidectomy Pain
}

Ismail Elahabadi', Alireza Khazaei ${ }^{2}$, Zahra Kamiab ${ }^{3}$, Masoumeh Taghizadeh ${ }^{4}$, Gholamreza Bazmandegan $^{5}$

1.Assistant Professor, Department of Surgery, Ali-Ibn Abi-Talib Hospital, School of Medicine, Rafsanjan University of Medical Sciences, Rafsanjan, Iran. ORCID ID: 0000-0003-1549-6697.

2. Assistant Professor, Department of Surgery, School of Medicine, Zahedan University of Medical Sciences, Zahedan, Iran. ORCID ID: 0000-0002-6497-2429.

3. Assistant Professor, Department of Family Medicine, School of Medicine; Head of Clinical Research Development Unit, Ali-Ibn Abi-Talib Hospital, Rafsanjan University of Medical Sciences, Rafsanjan, Iran. ORCID ID: 0000-0001-6670-1828.

4. Assistant Professor, Department of Surgery, School of Medicine, Ali-Ibn Abi-Talib Hospital, Rafsanjan University of Medical Sciences, Rafsanjan, Iran. ORCID ID: 0000-0002-8699-7782.

5. Assistant professor, Department of Family Medicine, School of Medicine; Clinical Research Development Unit, Ali-Ibn Abi-Talib Hospital, Rafsanjan University of Medical Sciences, Rafsanjan, Iran., (Corresponding Author), Tel: +983434280185, Email: bkhrbster@gmail.com, ORCID ID: 0000-0002-5379-5623.

\begin{abstract}
Background and Aim: Anal surgery is relatively common, and rarely is performed as an outpatient opration procedure due to concerns about postoperative pain. The present study aimed to compare the effects of rectal acetaminophen and diclofenac suppositories on pain control after anal surgery (hemorrhoidectomy) in adult patients.

Materials and Methods: This clinical trial study was conducted in Zahedan in 2013 and included 70 patients who underwent hemorrhoidectomy. The patients were divided into two groups, one group received rectal acetaminophen and the other one used diclofenac suppositories. Pain intensity was measured by visual analogve score system at different time intervals $(0,2,4,12$, and 24 hours). Data were analyzed by relevant statistical test.

Results: Pain intensity at different times in the study was significantly lower in the diclofenac suppository group compared to that in the acetaminophen suppository group. The mean time intervals needed for drug administration in the diclofenac group was $183.14 \pm 26.98$ minutes and $166.85 \pm 27.30$ minutes in the acetaminophen group; therefore, a statistically significant difference was observed between the two groups.

Conclusion: Diclofenac suppository showed a better analgesic effect than acetaminophen suppository in post-hemorrhoidectomy pain management. Use of diclofenac suppositories can have more satisfactory results in reducing postoperative pain.

Keywords: Acetaminophen suppository, Diclofenac suppository, Hemorrhoidectomy

Received: May 29, $2019 \quad$ Accepted: Apr 17, 2021

How to cite the article: Ismail Elahabadi, Alireza Khazaei, Zahra Kamiab, Masoumeh Taghizadeh, Gholamreza Bazmandegan. Comparison of the effects of diclofenac and acetaminophen suppositories on post hemorrhoidectomy pain SJKU 2021;26(4):50-58.

Copyright @ 2018 the Author (s). Published by Kurdistan University of Medical Sciences. This is an open access article distributed under the terms of the Creative Commons Attribution-Non Commercial License 4.0 (CCBYNC), where it is permissible to download, share, remix, transform, and buildup the work provided it is properly cited. The work cannot be used commercially without permission from the journal
\end{abstract}




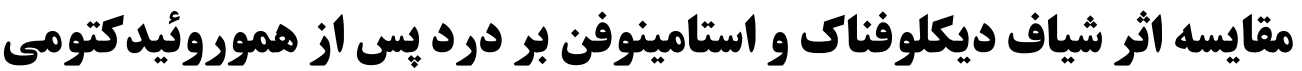

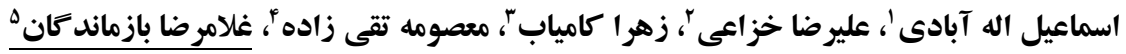

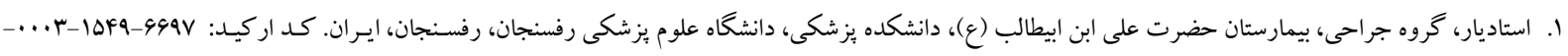

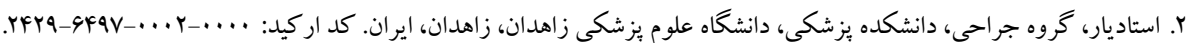

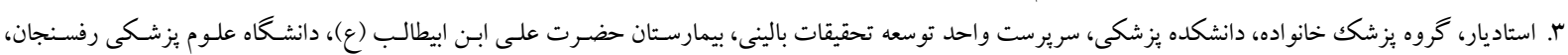
رفسنجان، ايران. كد اركيد:

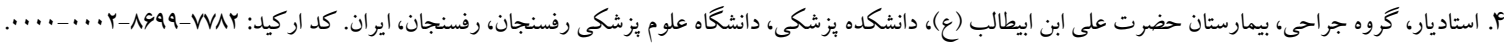

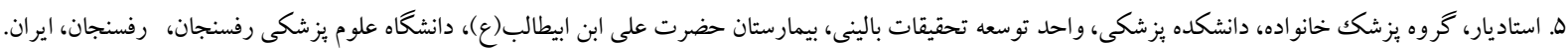

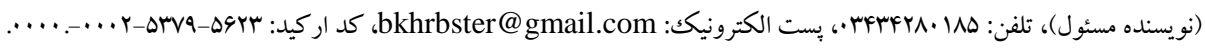

جكيده زمينه و هدف: جراحىهاى آنال از جراحىهاى نسبتاً شايع مىباشند و به دليل نگر انى در مورد درد بِ از عمل كمتر به صورت سريائى انجام مى شوند. هدف مطالعه حاضر، مقايسه اثرات شياف اسـتامينوفن و شياف ديكلوفنـاكك ركتـال در كنتـرل درد يسس از اعمال جراحى آنال (هموروييد كتومى) در بيماران بالغ بود. مواد و روشها: در اين مطالعه كار آزمـايى بـالينى كـه در شـهر زاهـدان در سـال بهبا انجـام شـد، تعـداد ·V بيمـار كـه تحـت هموروييد كتومى قرار گرفته بودند در دو گروه دريافت كننده شياف ديكلوفناكك و استامينوفن تحت بررسى قرار گرفتند. شدت درد

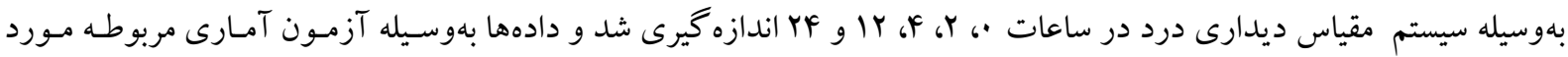
آناليز قرار خرفتند. يافتهها: شدت درد در زمانهاى مورد بررسى بهطور قابل توجهى در گروه شياف ديكلوفنـاكى كمتر از گروه شـياف استامينوفن

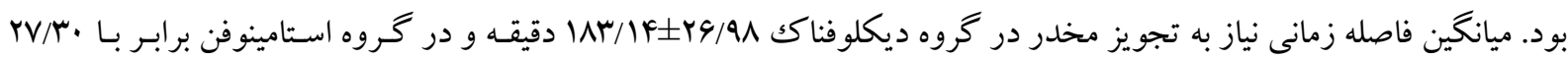
194/194 دقيقه بود و از اين جهت بين دو كروه تفاوت آمارى معنىدارى مشاهده شد. نتيجه كيرى: شياف ديكلوفناكك نسبت به استامينوفن اثر ضد درد بهترى در كاهش درد بعد از هموروييـدكتومى دارد. اسـتفاده از شياف ديكلوفناكك در كاهش درد بس از عمل مى تواند نتايج رضايتبخش ترى داشته باشد. كلمات كليدى: شياف استامينوفن، شياف ديكلوفناكك، هموروييد كتومى وصول مقاله: A/ / 
مشخصى همـراه اسـت ( • (V-1). نتسايج مطالعـات قبلى در خصوص استفاده از انواع داروهاى ضـد درد غير استروئيدى

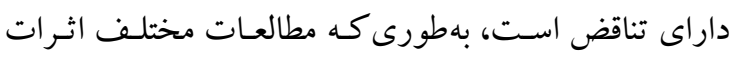

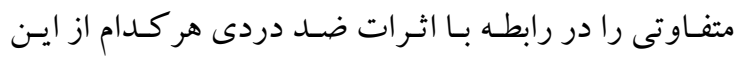

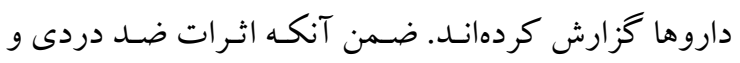
ضـدالتهابى و نيز عـوارض داروهـاى موجـود در ايـن دسته دارويى هم با يكديخر متفاوت است برخى مطالعـات نيـز بـــ

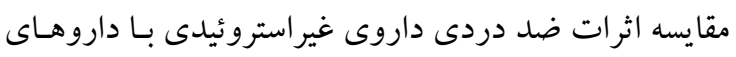

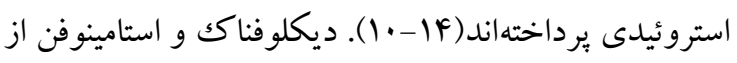

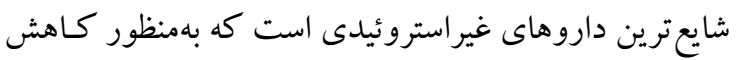
درد پٍ از عمل استفاده مى شود(1)-ه|). همجنين مطالعات

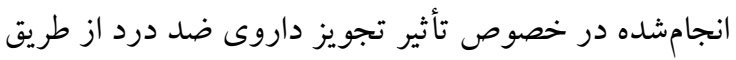

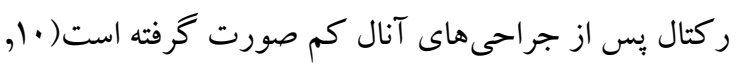

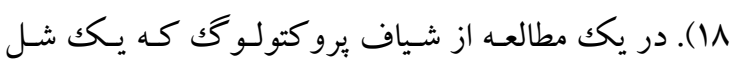

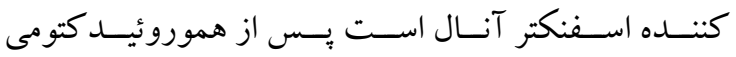

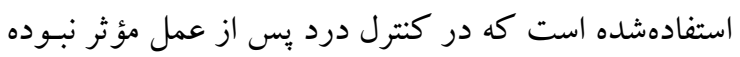

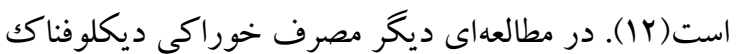

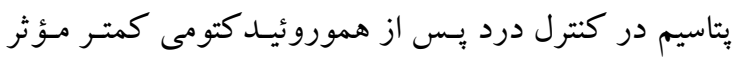
بوده است(r) ). در مطالعهاى شـياف ديكلوفنـاك در كنترل درد بِس از هموروئيسدكتومى مـؤثرتر از شـياف اسـتامينوفن

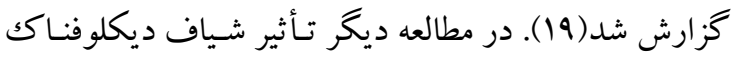

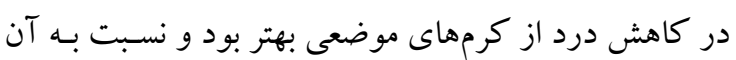

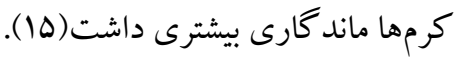

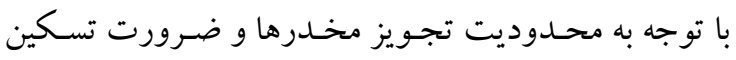

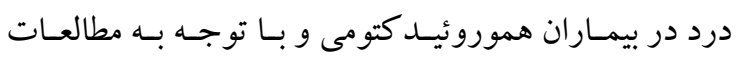

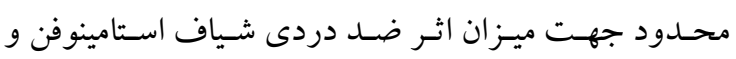

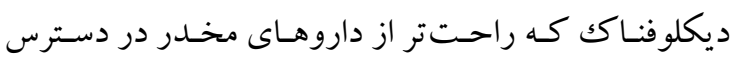

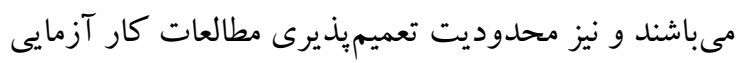

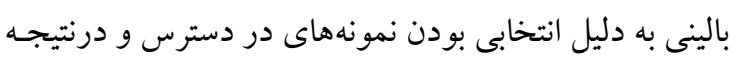

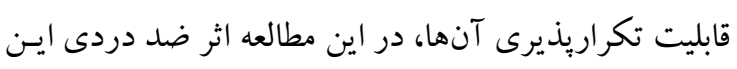
دو دارو بهصورت شياف موردبر رسى قرار گرفته است.
مقدمه هموروييـــ يكـى از شــايع ترين بيمارىهــاى آنور كتـال و مهـ

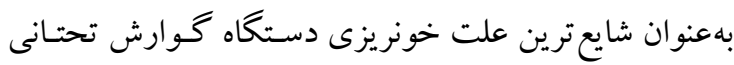

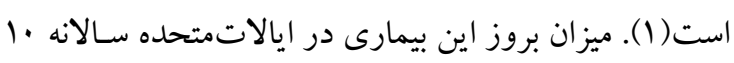

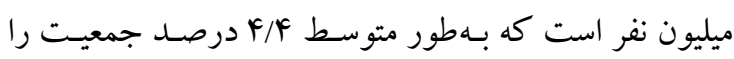

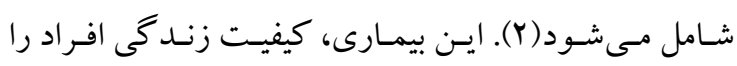
بهشدت تحـت تأثير قـرار مسىدهـد(r). تـاكنون روشهـاى

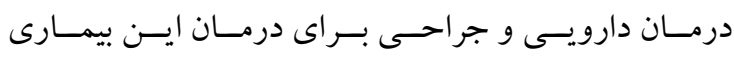
مورداستفاده قرار گرفته است(f). در حال حاضـر هـيج آمـار دقيقى درباره ميزان كسترش اين بيمارى در بين مـردم ايـران وجود ندارد، باينحال در يكك مطالعه انجامشده در جمعيت كشـور اسـتر اليا ميـزان شـيوع آن در حسـود هوب٪ بيانشـده است( (1). علائم خفيف اين بيمارى با درمان طبى قابلدرمـان بوده؛ ولى درمان ايدئال براى حالت يِيشرفته بيمارى، جراحى

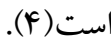
هموروييــد كتومى بـهـعنوان يـكك روش درمـان جراحسى در درجه هاى بالاتر هموروييد مورداستفاده قـرار مى گيـرد و در حال حاضر بـهـعنوان درمـان اسـتاندارد ايـن بيمـارى شـناخته مىشـود (4-4). هموروييـد كتومى بـاز يـا بسـته از شـايع ترين روشهـاى جراحسى هموروييــ اسـت؛ ولى اسـتفاده از ايـن روش درمانى معمولاً معايب و عـوارض مانـــ؛ دوره درمـان

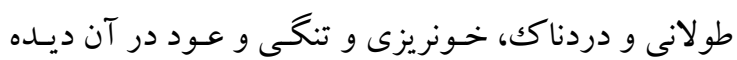

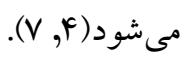
درد از عوارض بسيار بد اين روش درمانى است كـه معمـولاً بعد از عمـل بــراى بيمـاران اتفـاق مى افتـــ. امـروزه بـهـمنظور كــاهش درد يـس از عمــل جر احسى، معمــولاً اسـتفاده از Nاروهـاى ضــدالتهابى غير اسـتروئيدى ( Non-steroidal anti-inflammatory drugs, NSAIDs

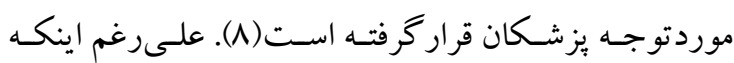
استفاده از NSAIDs موجب كاهش نياز به مخدر مىشـوند و كنترل مناسب درد يس از عمل مى شود؛ ولى تجويز آنهـا

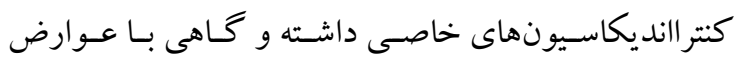


تحت بلو كك اسيينال و در يوزيشن ليتوتومى و بـا يـك روش

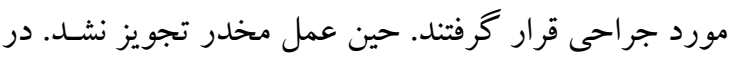
پايان عمل بر اساس جدول بلوككهاى تصادفى از شيافهاى

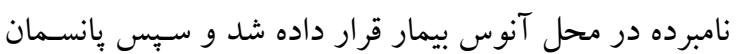

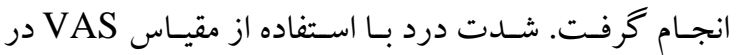

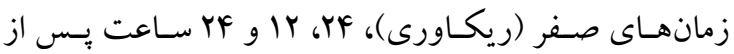

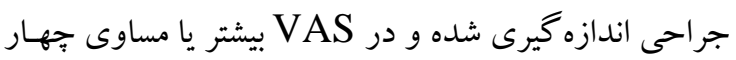
مخدر تزريق مىشد. فاصله زمانى تا نياز به مخدر وريدى يـا عضلانى بس از تعبيه شياف و عوارض احتمالى در بيمـاران

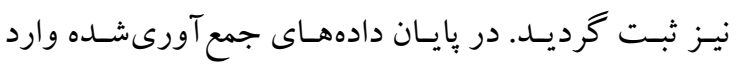

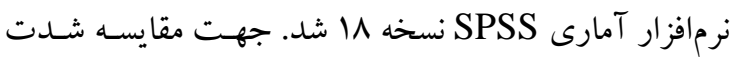

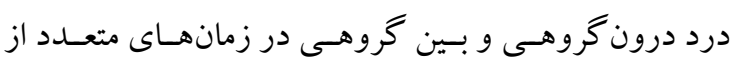
آزمسون انـدازههاى تكــرارى ( Repeated measures (ANOVA و جهت كنترل تصادفى سازى قبل از مداخله و

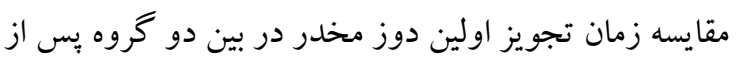
كنتـرل بيشفرضهـا (برقـرارى نرمـاليتى و آزمهون لـون) از

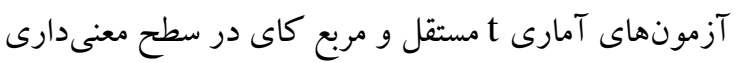

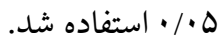

\section{يافته ها}

در اين مطالعه در ابتدا تعداد VY بيمار با تشخيص هموروييـد تحت عمل جراحى هموروييد كتومى قراركرفته بودند كه بـهـ

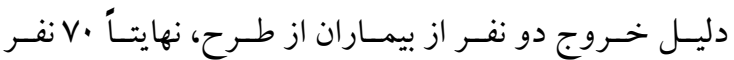
موردبررسى قرار كرفتند. نتايج نشـان داد كـه ميـانگين سـنى

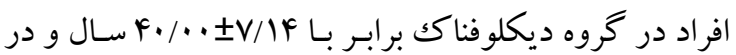
حروه اسـتامينوفن بر ابـر بـا r/· كروه ازنظر سنى تفـاوت آمـارى معنسىدارى مشـاهده نشــــ

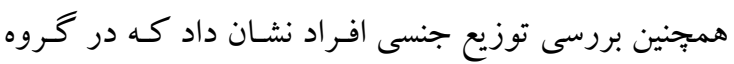

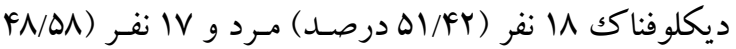
درصد) زن بودند، در گروه استامينوفن نيز ها نفـر (

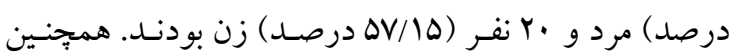
اندازه گيرى شدت درد قبل از مداخله بـه روش نمـره دهـى

\section{مواد و روشها - ماش}

اين مطالعه بهصورت كار آزمايى بالينى تصادفى دو سو كور

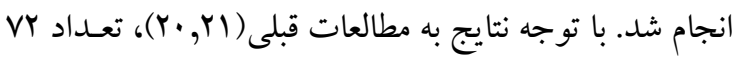
نفر از بيماران به روش نمونه گيرى در دسترس انتخاب شدند. افر اد شر كت كننده در مطالعه بهصورت تصادفى به دو گركروه تقسيمبندى شدند. اختصاص نمونهها به هر يكك از گروههاى درمانى بـهـ روش بلو ككبنـدى تصـادفى انجـام شـد. بـهـمنظور تقسيمبندى افر اد، تعـداد 9 بلـوكك بـا حجـم ^^يمـار در هـر بلوك مشخص شد كه به تعداد مسـاوى در هـر بلـوك قرار

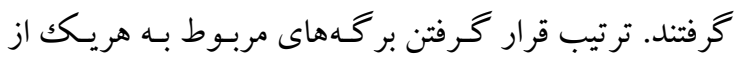
كروهها، با توجه به توزيع تصادفى در هر بلوكى انجام شد. با ترك توجسه بـه بلـوك تصـادفى انتخابشـــه، ترتيـب اختصـاص

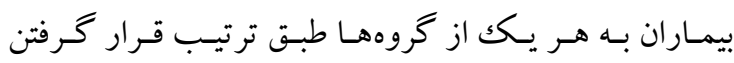
كارت ها در آن بلوكك بود؛ بنابراين با اتمام هر بلوكى ^ بيمار وارد مطالعه مىشدند كـه بهصورت مسـاوى †ا بيمـار از هـر

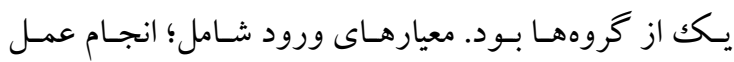
هموروئيد كتومى و رضـايت بـراى شـركت در مطالعسه بـود. معيارهـاى خـروج شـامل؛ سـابقه اخــلال انعقـادى، مصـرف روزانه داروهاى غير استروئيدى، سوءمصـرف الكـل يـا مـو اد مخدر، بيمـارى كبـدى، آسـم، بيمـارى مـزمن انسـدادى راه هوايى و سابقه اولسر ييتيكك بـود. قبـل از ورود بـه مطالعـه و

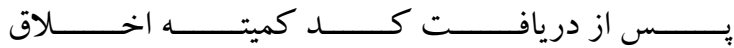
(IR.ZAUMS.REC.1392.967) و كــــ كــار آزمـايى ) بـالينى (IRCT2019.128042525N2) فرم رضـايتنامه رسمى از بيماران خرفتـه شـد. داده از طريـق معاينه بـالينى و

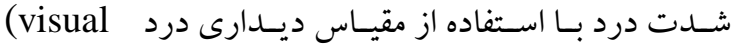
analogve score, VAS) محقق ساخته ثبت كرديد. نحوه مداخله به ايسن صسورت بـود كـه گروه اول دو شـياف

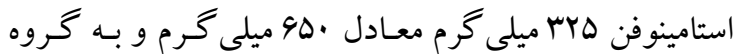
دوم شـياف ديكلوفنـاكك . ․ ميلى گــرم تجـويز شـد. فـرد ارزيابى كننده و بيمار از نوع شياف مطلع نبودند. تمام بيماران

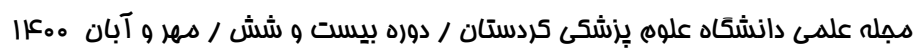




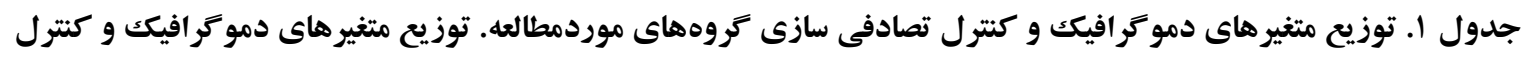

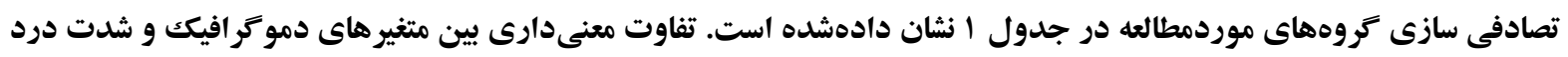

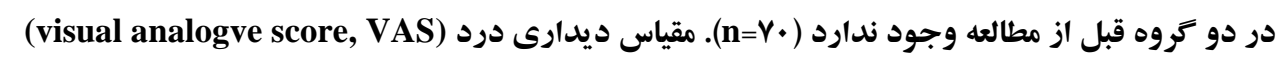

\begin{tabular}{|c|c|c|c|c|}
\hline P-Value & كروه استامينوفن & كروه ديكلوفناكى & \multicolumn{2}{|c|}{ متغير / كروهها } \\
\hline \multirow[t]{2}{*}{.1910} & $r q / / q \pm V / \cdot r$ & $r \cdot \pm V / l F$ & \multicolumn{2}{|c|}{ سن (ميانكين × انحراف معيار) } \\
\hline & & & \multicolumn{2}{|c|}{ شدت درد (VAS) قبل از } \\
\hline$\cdot / N+q$ & $I / N F \pm I / N V$ & $G Y / I \pm 1 / F V$ & \multicolumn{2}{|c|}{ مداخله (ميانكيند انحر اف } \\
\hline \multirow[t]{2}{*}{$\cdot / 4 \mid r$} & $1 \Delta(/ / . F Y / \Delta \Delta)$ & $1 \Lambda(\% . \Delta 1 / F r)$ & مرد & جنسيت فراوانى \\
\hline & $r \cdot(/ / \Delta V / / \Delta)$ & $\operatorname{IV}(/ / .4 \Lambda / \Delta \Lambda)$ & زن & درصد) \\
\hline
\end{tabular}

اختلاف معنى دارى بين سدت درد دو گحروه مشاهده نشـد

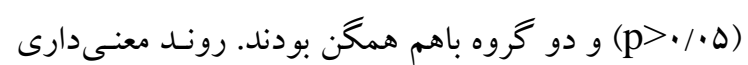

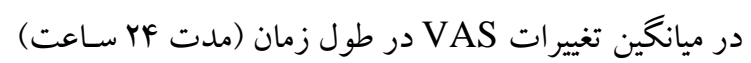

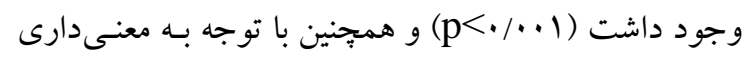

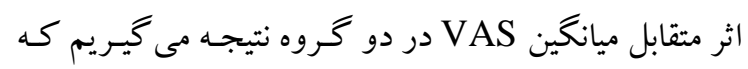

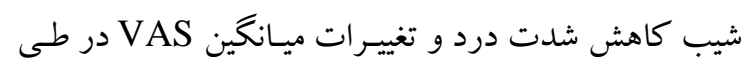

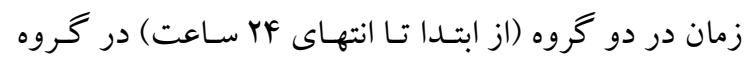
ديكلوفناك بيشتر است(جدول با، نمودار (1).
شــت درد بهوسـيله سيسـتم امتيـازدهى VAS در فواصـل

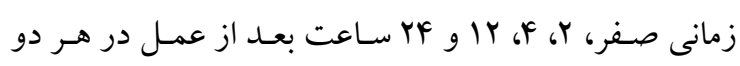
گروه سنجيده شد. براى مقايسه ميانگين تغييرات متغير درد برد

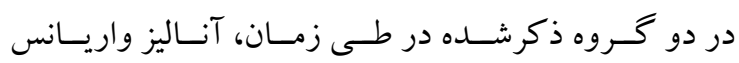

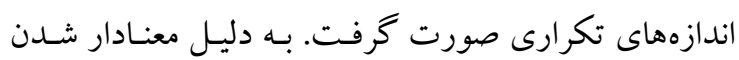

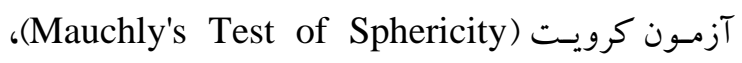

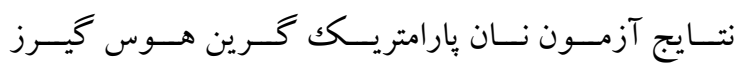
كزارش شده اسـت. بـهور كلى (Greenhouse-Geisser) در مسورد متغيــر شـاخص درد (VAS) در ابتــداى مطالعـه

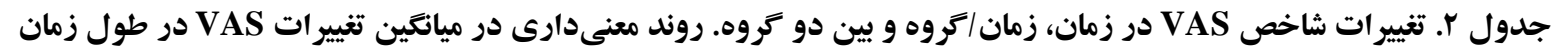

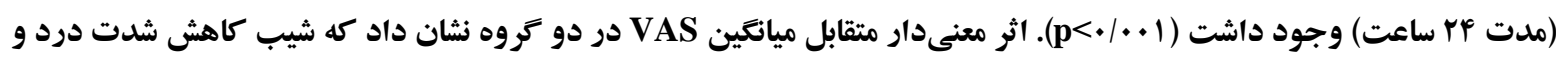

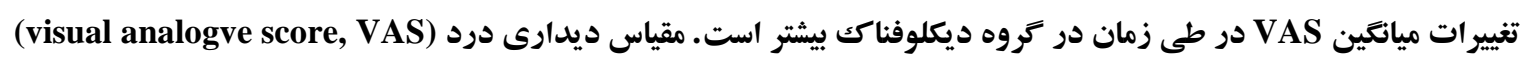

\begin{tabular}{|c|c|c|c|c|c|}
\hline P-Value & ميانكين مربعها & $\mathbf{F}$ & df & & متغير \\
\hline 国 $\cdot / \cdot \cdots$ & $19 \cdot / 9 Y 9$ & $1 \cdot r / \cdot r q$ & $r / 910$ & زمان & شاخص VAS \\
\hline$\cdot / 1 \cdot \Delta$ & $r / V 9 D$ & Y/IFF & $r / 910$ & زمان/ گروه & ا گرين هوس گيرز \\
\hline.$/ . r$ & rQ/vAr & $\Delta / 9 \Lambda$ & 1 & بين دو گروه & \\
\hline
\end{tabular}




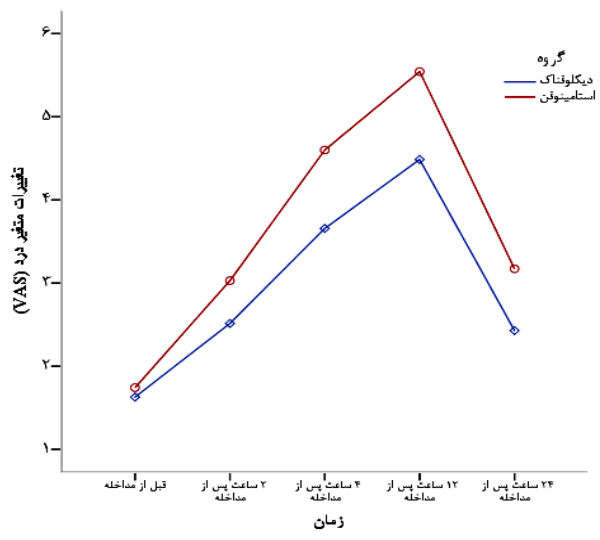

نمودار ا. روند تغييرات شاخص VAS در بين دو كروه در طول زمان. شيب كاهش شدت درد و تغييرات ميانكين VAS در طي زمان در كروه ديكلوفناكى بيشتر مىباشد. مقياس ديدارى درو دود (visual analogve score, VAS)

از كروه دريافت كنــده شـياف اسـتامينوفن اسـت و درنتيجـهـ شـياف ديكلوفنـاكك اثر طـولانى ترى در كنتـرل درد بعـد از

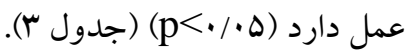

مسـدتزمان نيـاز بـه تجـويز اولـين مخــدر در بـين دو گــروه اندازه گيرى شـد. نتـايج نشـان داد كـه ايسن زمـان بهصورت معنى دارى در گروه دريافت كننده شياف ديكلوفنـاكك بيشتر

جدول r. فاصله زمانى نياز به تجويز اولين مخدر يس از عمل برحسب كروه موردمطالعه. فاصله زمانى نياز به تجويز اولين مخدر

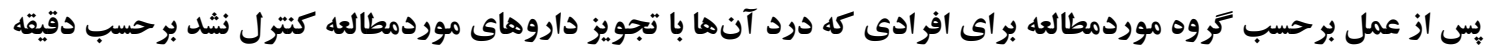

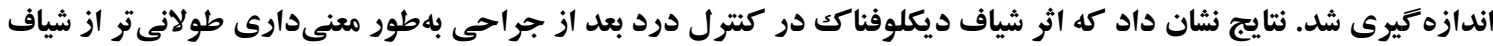
استامينوفن است (ه) (

\begin{tabular}{|c|c|c|}
\hline P-Value & فاصله زمانى نياز به تجويز مخدر (دقيقه) & 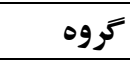 \\
\hline \multirow[t]{2}{*}{.$/ \cdot 1 \mathrm{f}$} & $|\Lambda r / Y q \pm| F / 9 \Lambda$ & ديكلوفناكك \\
\hline & $199 / \mathrm{VV} \pm \wedge \Delta / \mathrm{r}$ & 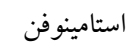 \\
\hline
\end{tabular}

ديكلوفناكك اثر طولانى ترى در كنترل درد نسبت بـه شياف استامينوفن داشت. درمجموع نتايج اين مطالعه نشـان داد كـه تجويز شياف ديكلوفناكك نسبت به شياف استامينوفن بسس از جراحى هموروئيد كتومى، موجب كنترل بهتر درد مىشود. بـر اسـاس مطالعـات موجـود، تجـويز NSAIDs در حـوالى عمل جراحى، موجب كـاهش قابل توجـه درد بـس از عمـل جراحى، بـروز كمتـر تهـوع و اسـتفراغ و باز گشـت سـريعتر

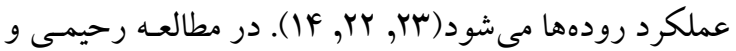
همكاران، تأثير شياف ديكلوفنـاكك در كـاهش درد بيشـتر از اسـتامينوفن بـود كــه همسـو بــا يافتـه هاى مطالعـه حاضـر است(19). در مطالعـه ديخـر كـه بـهنظور بررسى اثر ضـــ جراحى آنال عموماً بهصورت غير سـريايى انجـام مىشـود و علت اصلى اين مسئله نگر انى از عدم كنترل درد يس از عمل و مشكلات مربوط به آن است(V, \&, \&). امـروزه استفاده از داروهاى NSAIDs براى كاهش درد بيمار ان يسس از عمل مرسوم شده است(V,N). يافته هاى مطالعه حاضر نشان داد كه شدت درد در كروه دريافت كننده شياف ديكلوفناكك بهطور معنى دارى كمتر از كـروه دريافت كنتـده شـياف اسـتامينوفن بــود. مــدتزمان نيـاز بـهـ تجـويز اولـين مخــدر در خـروه دريافت كننده شياف ديكلوفناكك بهطور معنسى دارى بيشـتر از كــروه شـياف اســتامينوفن بــود؛ بــهبارتديخر شـياف

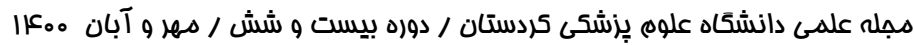


ديكلوفناك را با استامينوفن و شبه دارو بر دردهاى متوسط تا

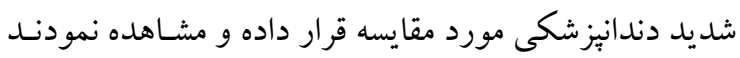
كه ديكلو فناكك بيش از استامينوفن و استامينوفن بيشتر از شـبه دارو در تسكين اين نوع دردها مؤثر است(بو دو).

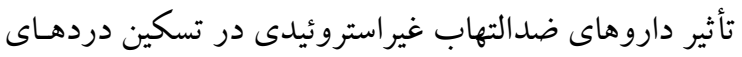

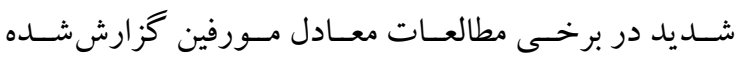

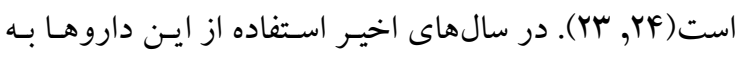

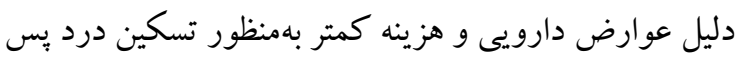

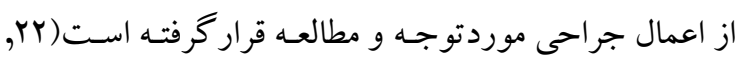

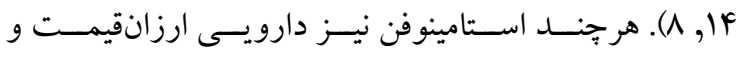

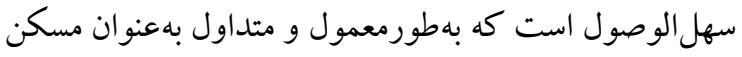

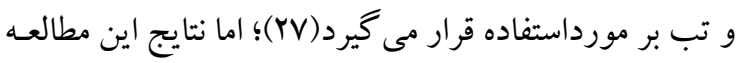

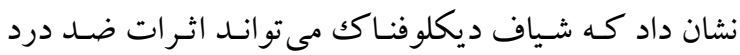
بيشتر و طو لانى ترى نسبت شياف استامينوفن داشته باشد.

\section{نتيجه كيرى}

بـر اسـاس يافتـهاى مطالعه حاضـر، اثر ضـــ دردى شـياف ديكلوفناكك بيشتر و طولانى تر از شياف استامينوفن در كنترل

$$
\text { درد بعد از هموروييد كتومى دارد. }
$$

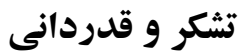

منابع مالى اين مطالعه از طريق دانشكاه علوم بز شكى زاهى زاهدان تامين شده است. هيج كدام از نويسند كان اين مطالعهه، افراد و يا دستگاهها تعارض منافعى براى انتشار اين مقاله ندارنـد.

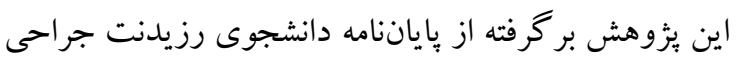

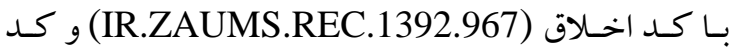

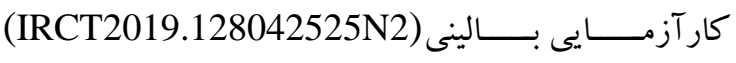
مىباشد. نويسند كان اين مقاله از بخش جراح احى و اتاق عمـل

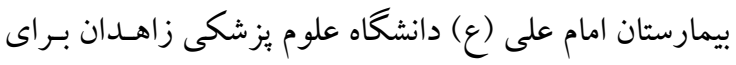

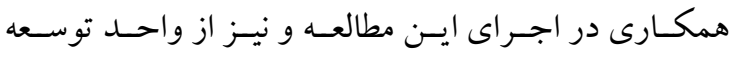

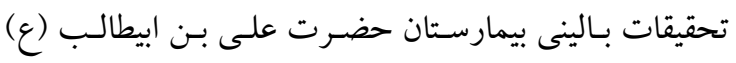

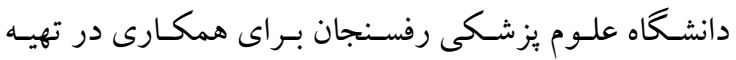
كزارش اين بروزه، تشكر و قدردانى مى دمايند.
دردى ديكلوفناكك و كرم بى حس كننده موضعى بـود، نتايج

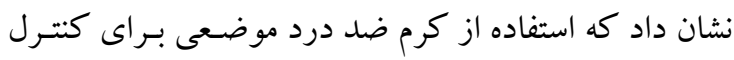

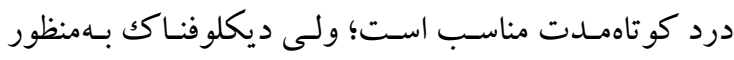

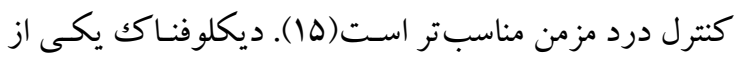

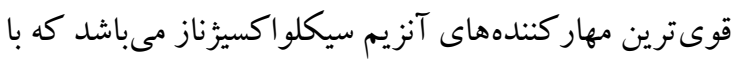

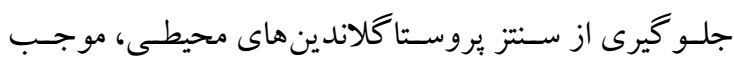
كاهش التهاب و بديده بروز درد مىشود (IF (IF).

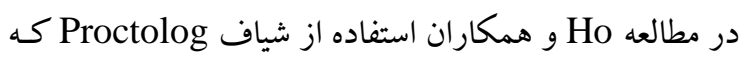

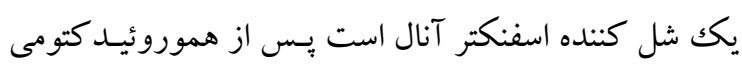

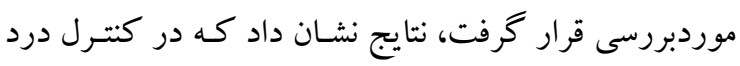

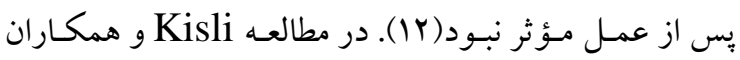

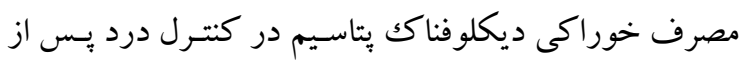

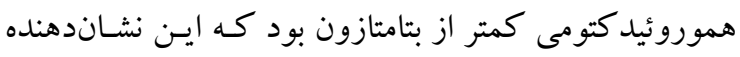

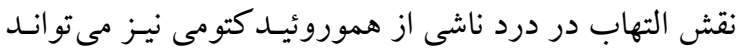

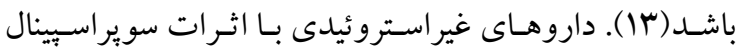
آنتىنوسيسـيتيو (supraspinal and anti-nociceptive)

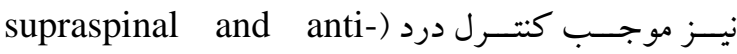
nociceptive

و ديكلوفناكك در كنترل درد نيز گزارش شده است (YF).

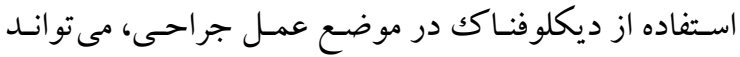
علاوه بر اثرات ضد دردى، اثرات ضدالتهابى رانيز بهتر ايفـا

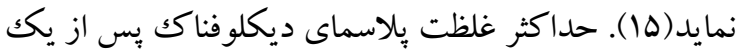

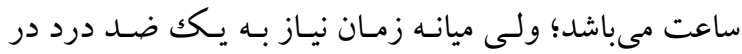
مطالعه حاضر در گروه ديكلوفناك در حدود سه ساعت بود. كه مىتواند نشاندهنده اثر ضـالتهابى NSAIDs در محل

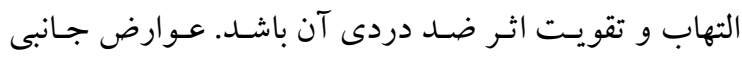

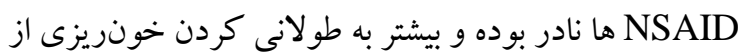

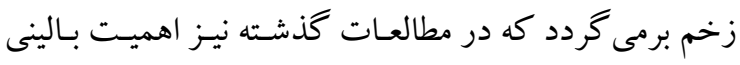

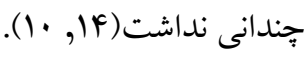

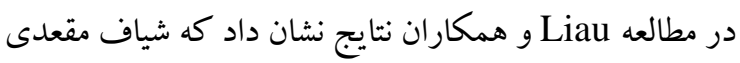
ديكلوفناكك بهاندازه كتـورولاكك داخل وريــى در تسكين

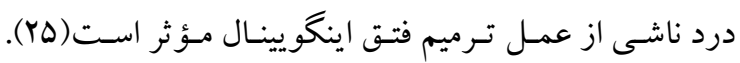

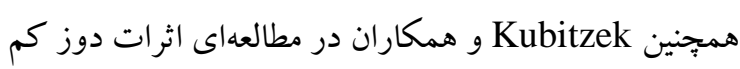


1.Gallo G, Sacco R, Sammarco G. Epidemiology of Hemorrhoidal Disease. Hemorrhoids. 2018:3-7.

2.Riss S, Weiser FA, Schwameis K, Riss T, Mittlböck M, Steiner G, et al. The prevalence of hemorrhoids in adults. Int J Colorectal Dis. 2012;27(2):215-20.

3.Szyca R, Leksowski K. Assessment of patients' quality of life after haemorrhoidectomy using the LigaSure device. Wideochir Inne Tech Maloinwazyjne. 2015;10(1):68.

4.Lohsiriwat V. Treatment of hemorrhoids: A coloproctologist's view. World J Gastroenterol. 2015;21(31):9245.

5.Lohsiriwat V. Hemorrhoids: from basic pathophysiology to clinical management. World J Gastroenterol. 2012;18(17):2009-17.

6.Yeo D, Tan KY. Hemorrhoidectomy-making sense of the surgical options. World J Gastroenterol. 2014;20(45):16976-83.

7.Sun Z, Migaly J. Review of hemorrhoid disease: presentation and management. Clin Colon Rectal Surg. 2016;29(01):022-9.

8.Rahimi MO, Makarem J, Maktobi M. Post hemorrhoidectomy pain control: rectal Diclofenac versus Acetaminophen. Tehran Univ Med J. 2009;67(1).

9.Higuero T, Abramowitz L, Castinel A, Fathallah N, Hemery P, Duhoux CL, et al. Guidelines for the treatment of hemorrhoids. J Visc Surg. 2016;153(3):213-8.

10.Scott RM, Jennings PN. Rectal diclofenac analgesia after abdominal hysterectomy. Aust N Z J Obstet Gynaecol. 1997;37:112-4.

11.Ng A, Parker J, Toogood L, Cotton BR, Smith G. Does the opioidsparing effect of rectal diclofenac following total abdominal hysterectomy benefit the patient? $\mathrm{Br} \mathrm{J}$ Anaesth. 2002;88:714-6.

12.Ho YH, Seow-Choen F, Low JY, Tan M, Leong AP. Randomized controlled trial of trimebutine (anal sphincter relaxant) for pain after haemorrhoidectomy. $\mathrm{Br} \mathrm{J}$ Surg. 1997;84:377-9.

13.Kisli E, Baser M, Guler O, Aydin M, Kati I. Comparison of the analgesic effect of betamethasone and diclofenac potassium in the management of postoperative haemorrhoidectomy pain. Acta Chir Beig. 2005;105:388-91.

14.Hokki H. Non steroidal anti inflammatory drugs for post operative pain: a focus on children. Paediatr Drugs. 2003;5(2):103-23.

15.Rahimi M, Kazemeini AR, Pourtabatabaei N, Honarmand AR. Comparison of topical anesthetic cream (EMLA) and diclofenac suppository for pain relief after hemorrhoidectomy. Surg today. 2012;12:1201-5.

16.Abdurahman S.AL-Mulhim,Adel M.Ali,Nabil AL-Masuaod,Adel A lvahidi.post hemorrhoidectomy pain,A randomized controlled trial. Saudi Med j. 2006;27(10):1538-41.

17.Dart RC, Green JL, Bogdan GM. The safety profile of sustained release paracetamol during therapeutic use and following overdose. Drug Saf. 2005;28(11):1047-56.

18.Vyvyan HA, Hanafiah Z. Patients' attitudes to rectal drug administration. Anaesthesia. 1995;50:983-4.

19.Rahimi M,Makarem J, Maktobi M. posthemorrhoidectomy pain control;rectal diclofenac versus acetaminophen. Tehran Univ Med J. 2009:926-930.

20.Rahimi M MJ, Maktobi M. post hemorrhoidectomy pain control; rectal diclofenac versus acetaminophen. Tehran Univ Med J. 2009;66(12):926-30.

21.Ala S, Saeedi M, Eshghi F, Rafati M, Hejazi V, Hadianamrei R. Efficacy of $10 \%$ sucralfate ointment in the reduction of acute postoperative pain after open hemorrhoidectomy:

هبلم علدى دانشكاه علوه بِزشكى كردستان / دوره بيست و شش / دعر و آبان م.ع|| 
a prospective, double-blind, randomized, placebo-controlled trial. World J Surg. 2013;37(1):233-8.

22.Hommer JJ, Frewer JD, Swallow J, Semple P. An audit of post operative analgesia in children following tonsillectomy. J Laryngol Otol. 2002; 116(5): 367-70. .

23.Manson L, Edwards JE, Moore RA, McQuay HJ. Single dose oral naproxen for acute post operative pain: a quantitative systemic review. Anesthesiology. 2003;3:4-9.

24.Oztekin S, Hepaguslar H, Kar AA, Ozzeybek D, Artikaslan O, Elar Z. Preemptive diclofenac reduces morphine use after remifentanil based anesthesia for tonsillectomy. Ped Anaesthesia. 2002;12:694-99.

25.Liau W, Wong C, Goh LC, Patil NG, Lee F. Prospective randomized trial of preemptive analgesic following ambulatory inguinal hernia repair: Intravenous ketorolac versus diclofenac suppository. ANZ J Surg. 2002;72(10):704-7. .

26.Kubitzek F, Ziegler G, Gold MS, Lui JM, Lonescu E. Analgesic efficacy of low dose diclofenac versus paracetamol and placebo in post operative dental pain. J Orofac Pain. 2003;17(3):237-44. .

27.Kvalsvik O, Borchgrevink PC, Hagen L, Dale O. Randomized, double-blind, placebocontrolled study of the effect of rectal paracetamol on morphine consumption after abdominal hysterectomy. Acta Anaesthesiol Scand. 2003;47:451-6. 